\title{
Frequency and Factors Associated with Depression in Rheumatoid Arthritis in African Black Patients: Case-Control Study
}

\author{
Wendlassida Joelle S. Zabsonré Tiendrébéogo ${ }^{1^{*}}$, Kaboré Fulgence ${ }^{1}$, Nanema Désiré ${ }^{2}$, \\ Savadogo Binta ${ }^{1}$, Dravé Alassane ${ }^{3}$, Sougué Charles ${ }^{1}$, Soupougdou Camille¹, Ouédraogo Moussa ${ }^{1}$, \\ Ouédraogo Dieu-Donné1
}

\footnotetext{
${ }^{1}$ Department of Rheumatology, University Hospital of Bogodogo, Ouagadougou, Burkina Faso

${ }^{2}$ Department of Psychiatry, University Hospital of Ouahigouya, Ouahigouya, Burkina Faso

${ }^{3}$ Department of Neurology, University Hospital of Ouahigouya, Ouahigouya, Burkina Faso

Email: *t_joelle@hotmail.com
}

How to cite this paper: Zabsonré Tiendrébéogo, W.J.S., Fulgence, K., Désiré, N., Binta, S., Alassane, D., Charles, S., Camille, S., Moussa, O. and Dieu-Donné, O. (2019) Frequency and Factors Associated with Depression in Rheumatoid Arthritis in African Black Patients: Case-Control Study. Open Journal of Rheumatology and Autoimmune Diseases, 9, 35-41.

https://doi.org/10.4236/ojra.2019.92004

Received: February 6, 2019

Accepted: May 21, 2019

Published: May 24, 2019

Copyright $\odot 2019$ by author(s) and Scientific Research Publishing Inc. This work is licensed under the Creative Commons Attribution International License (CC BY 4.0).

http://creativecommons.org/licenses/by/4.0/ (c) (i) Open Access

\begin{abstract}
Objective: To study the frequency and factors associated with depression in rheumatoid arthritis (RA) among Black African patients. Patients and methods. It was a case-control study with a group of patients with RA (case) and a group of healthy subjects without rheumatoid arthritis (controls) matched by age and sex. All patients admitted to the rheumatologic department during February 2015 to July 2015 for rheumatoid arthritis meeting the criteria ACR/EULAR 2010, were included. Patients with high blood pressure, diabetes mellitus, renal failure or HIV infection have been excluded. Depression was assessed by the Hamilton Rating Scale for Depression. Results. Fifty patients with RA were included and compared to 100 healthy controls. For RA patients, it was $39(78 \%)$ female and $11(22 \%)$ male with a sex ratio of 0.28 . In the control group, it was $77(77 \%)$ female and $23(23 \%)$ male with a sex ratio of 0.29 . Twenty-seven (54\%) patients with RA had depression compared with $17(17 \%)$ subjects in the control group $(\mathrm{p}=0.000)$. Impaired quality of life and a DAS 28 score greater than 3.2 were statistically associated with depression during RA with a $\mathrm{p}$ value respectively of 0.021 and 0.0000231 . Conclusion: Depression is significantly more common during RA than in non-RA controls. RA patients should be screened routinely for depression in order to ensure improved treatment and management.
\end{abstract}

\section{Keywords}

Rheumatoid Arthritis, Depression, Africa, Burkina Faso 


\section{Introduction}

Rheumatoid arthritis (RA) is the most common chronic inflammatory rheumatism. It is potentially erosive and distorting. It affects $0.3 \%$ to $1 \%$ of the world's population [1]. In sub-Saharan Africa, the prevalence of RA varies from $0 \%$ to $1 \%$ depending on rural or urban population [2] [3]. Its clinical and serological feature is similar to those of RA Caucasian patients except for the rarity of rheumatoid nodules [4]. The prevalence of depression ranges from $16.8 \%$ to $63.6 \%$ in RA according to diagnostic tools [5] [6] [7] [8]. RA and depression are two diseases that have an intricate relationship with reciprocal influences and even some commonalities. In fact, depression and anxiety are associated with a poor quality of life and a poor therapeutic response during RA [9]. In addition, depression has been shown to be a risk factor for mortality during RA [10]. The diagnosis of depression is therefore important during RA. If there is data concerning Caucasian subject, few studies have been done the expensive black African subject. The aim of this work was to study the frequency and risk factors of depression during RA in a black population in sub-Saharan Africa.

\section{Patients and Methods}

It was a case-control study involving a group of patients with RA (case) and a group of healthy subjects without rheumatoid arthritis (controls) matched by age and sex. The study took place in the rheumatology department of university hospital of Bogodogo in Ouagadougou from February 2015 to July 2015. This department is the only one in the country running a rheumatology consultation clinic. All patients admitted to this department during this period for rheumatoid arthritis and meeting the ACR/EULAR 2010 for RA criteria were included [11]. Patients with high blood pressure, fibromyalgia syndrome, chronic widespread pain, diabetes mellitus, renal failure or HIV infection have been excluded. The controls were recruited consecutively among the caregivers, the trainees and the health staff. The interrogation made it possible to exclude from the control group all those who suffered from any disease. Depression was assessed by the Hamilton Rating Scale for Depression (HRSD) [12] [13]. This is a face-to-face questionnaire with seventeen items: depressed mood, feelings of guilt, suicide, insomnia of the beginning of the night, insomnia of the middle of the night, insomnia of the morning, work and activity, slowing down, agitation, psychic anxiety, somatic anxiety, gastrointestinal somatic symptoms, general somatic symptoms, genital symptoms, hypochondria, weight loss, and awareness. This scale classifies depression as Absence of depression (0 - 9), mild depressive (10 to 13), mild to moderate depressive (14 to 17), moderate to severe depressive (over 18). The quality of life of the patients was appreciated by Health Assessment Questionnaires (HAQ) score [14]. HAQ score greater than 1.5 was consistent with an impairment of quality of life. The activity of RA was assessed by disease activity score-28 (DAS-28). RA was in remission when DAS $28<2.6$, low activity when DAS 28 is between 2.6 and 3.2 and active when DAS $28 \geq 3.2$ [15]. 
The determination of rheumatoid factor (RF) was carried out using the ELISA test and was considered as positive for level higher than 10 IU/l. The determination of Anticyclic citrullinated peptide antibodies (ACPA) was carried out using the Elisa CCP (Phadia, Uppsala, Sweden); any value higher than $10 \mathrm{IU} / 1$ was considered as positive. Data were entered on a microcomputer equipped with the statistical processing software EPI-INFO in version 7 for analyzes. An analytical study compared qualitative variables using the Pearson Chi 2 test with a 95\% confidence interval. For the comparison of means, the Student's test was used. The probability $\mathrm{p}$ is significant if $\mathrm{p}<0.05$. The evaluation of odds ratio (OR) has made to highlight the risks associated with a 95\% confidence interval and to evaluate their importance. The variable was considered a risk factor if OR $>1$. When the confidence interval (CI) contains the value 1 , the link between the variables is not statistically significant.

\section{Results}

Fifty patients with RA were included and matched to 100 healthy controls. In the RA group, there were 39 (78\%) female and 11 (22\%) male, the sex ratio was 0.28 . In the control group, there were 77 (77\%) female and 23 (23\%) male with a sex ratio of 0.29 . The difference was not statistically significant $(\mathrm{p}=0.890)$. The mean age was 42.74 years \pm 12.64 years with extremes of 17 and 76 years in the RA group and 42.47 years \pm 12.55 with extremes of 18 and 77 years in the controls $(\mathrm{p}=0.98)$.

The mean duration of progression of RA was $6.56 \pm 6.19$ years with extremes of 1 and 28 years. The mean DAS28 at the time of study of RA patients was 3.62 \pm 1.50 with extreme scores of 0.84 and 7.88 . DAS 28 was $<3.2$ in 19 (38\%) patients. Thirty-five patients (70\%) were able to achieve ACPA. The average level of ACPA was $136.64 \pm 163.26 \mathrm{IU} / \mathrm{ml}$ with extremes of 0.94 and $500 \mathrm{IU} / \mathrm{ml}$. Twenty-nine (82.86\%) patients were ACPA positive.

In the RA group, 27 (54\%) patients had depression compared with 17 (17\%) subjects in the control group $(\mathrm{p}=0.000)$. Table 1 shows the distribution of RA and controls by stage of depression. A DAS28 > 3.2 score was associated with depression ( $\mathrm{p}=0.0000231$ ). Table 2 gives the distribution of patients by risk factors for depression.

Table 1. Distribution of RA and controls by stage of depression.

\begin{tabular}{cccccc}
\hline & \multicolumn{3}{c}{ RA* $^{*}$} & \multicolumn{3}{c}{ Controls } \\
\hline & Number & $(\%)$ & Number & $(\%)$ & probability \\
\hline Mild depression & 13 & $(48.18)$ & 14 & $(82.35)$ & \\
Mild to moderate depression & 6 & $(22.22)$ & 3 & $(17.64)$ & \\
Moderate to severe depression & 8 & $(29.62)$ & 00 & $(0.00)$ & 0.0000026 \\
Total & 27 & $(100)$ & 17 & $(100)$ &
\end{tabular}

${ }^{*}$ RA: rheumatoid arthritis. 
Table 2. The distribution of patients by risk factors for depression.

\begin{tabular}{ccccc}
\hline & $\begin{array}{c}\text { With depression } \\
\mathbf{n}^{*}(\%)\end{array}$ & $\begin{array}{c}\text { Without dépression } \\
\mathbf{n}(\%)\end{array}$ & OR [95\% IC] & Probability \\
\hline Number & 27 & 23 & & \\
Age > 50 years & $6(22.22)$ & $9(39.13)$ & $0.4[0.12-1.52]$ & 0.19 \\
Female & $22(81.48)$ & $17(73.91)$ & $0.43[0.16-1.15]$ & 0.07 \\
Married & $15(55.56)$ & $17(73.97)$ & $0.44[0.13-1.46]$ & 0.17 \\
Evolution > 5 years & $12(44.44)$ & $8(34.78)$ & $0.64[0.16-2.47]$ & 0.48 \\
Stiffness & $9(33.33)$ & $5(21.74)$ & $1.8[0.50-6.43]$ & 0.36 \\
High HAQ & $19(70.37)$ & $8(29.63)$ & $9.26[1.06-80.93]$ & 0.021 \\
DAS28 > 3.2 & $24(88.89)$ & $7(30.43)$ & $18.28[4.1-81.39]$ & 0.0000231 \\
Deformations & $12(44.44)$ & $6(26.09)$ & $2.26[0.68-7.53]$ & 0.09 \\
ACPA** $(+)$ & $18(90.00)$ & $11(73.33)$ & $3.27[0.51-20.93]$ & 0.19 \\
Erosions & $7(31.82)$ & $7(38.89)$ & $0.73[0.19-2.7]$ & 0.64 \\
Corticoids use & $21(77.78)$ & $13(56.52)$ & $2.69[0.79-9.17]$ & 0.10 \\
\hline
\end{tabular}

${ }^{*}$ : number; ${ }^{* *}$ ACPA: Anti Citrullined Peptid Antibody.

\section{Discussion}

The frequency of depression was significantly higher in the RA group (54\%) than in healthy controls (17\%). The activity of the disease (DAS28) and an impairment of quality of life (HAQ) were statistically associated with the presence of depression.

RA is a chronic inflammatory rheumatism with an impact on several components of the patient's health. Yet nearly half of patients with RA, and followed up in a 3rd level structure, have depression that has never been diagnosed and managed [6]. Recently in China, Fux et al. in a meta-analysis that included 21 studies and 4447 RA patients found a prevalence of $48 \%$ depression [5]. This was $63.6 \%$ in a single-center Iranian series [7]. The incidence risk ratio of depressive disorders between RA patients and control patients was 2.20 (95\% confidence interval [CI], $1.84-2.61, \mathrm{P}, 0.001$ ) [14]. Depression seems to occur more frequently during the first five years after the diagnosis of RA [16] [17]. Indeed, $30 \%$ of 4187 patients with RA were diagnosed with depression after 5 years according to Jacob et al. [17]. Wang et al. conducted a retrospective study of a matched cohort of 18285 participants (3657 RA patients and 14628 control patients); During the 10-year follow-up period, 205 (11.2 per 1000 person-years) RA patients and 384 (5.1 per 1000 person years) control patients were diagnosed with depressive disorders. In RA patients, most depressive disorders $(\mathrm{n}=163$, $80 \%$ ) developed with five years of being diagnosed with RA [16]. Severe depression was found in approximately $30 \%$ of patients with RA and in no control. Cabrera-Marroquin et al. reported $30.8 \%$ cases of severe depression and emphasized poor compliance with poorer concordance with therapy [18].

The risk factors associated with depression are important to know because 
they are associated with high mortality during RA [10]. The activity of RA (DAS28) and impaired quality of life have been statistically associated with depression in our series. A high DAS 28 score is recognized by several authors as a risk factor for depression survivorship [8] [9]. This high DAS 28 score could be associated with the repercussions of depression on the subjective components of DAS 28 such as painful joints or verbal analog scale (VAS), but also because of non-compliance with treatment associated with depression [19] [20]. Few studies have found no association between disease activity and depression [7]. Age over 50 years and gender were not associated with depression in our study. However for Lin and al. age and gender are significantly related to the risk of depression in RA patients. In addition, the risk of depression was 19\% greater for subjects aged $\geq 70$ years compared with those aged $<18$ years. Compared with male gender, female gender was related to an adjusted hazard ratio of 1.77 for depression [20]. Our study, whose objective was to evaluate the frequency and the factors associated with RA depression in African black subjects, has limits including the small size of the RA population. The inclusion of a control group brings some power to the study, however other studies including larger numbers are needed before any definitive conclusion.

\section{Conclusion}

Depression is significantly more common during RA than in non-PR controls. RA patients should be screened routinely for depression in order to ensure improved treatment and management. In view of the small size of our sample, further studies are needed in order to draw definitive conclusions about the association of rheumatoid arthritis and depression in the African black subject, south of the Sahara.

\section{Conflicts of Interest}

The authors declare no conflicts of interest regarding the publication of this paper.

\section{References}

[1] Woolf, A.D. and Pfleger, B. (2003) Burden of Major Musculoskeletal Conditions. Bulletin of World Health Organization, 81, 646-656.

[2] Malemba, J.J., Mbuyi-Muamba, J.M., Mukaya, J., Bossuyt, X., Verschueren, P. and Westhovens, R. (2012) The Epidemiology of Rheumatoid Arthritis in Kinshasa, Democratic Republic of Congo: A Population-Based Study. Rheumatology (Oxford), 51, 1644-1647. https://doi.org/10.1093/rheumatology/kes092

[3] Silman, A.J., Ollier, W., Holligan, S., Birrell, F., Adebajo, A., Asuzu, M.C., Thomson, W. and Pepper, L. (1993) Absence of Rheumatoid Arthritis in a Rural Nigeria Population. Journal of Rheumatology, 20, 618-622.

[4] Ouédraogo, D.D., Singbo, J., Diallo, O., Sawadogo, S.A., Tieno, H. and Drabo, J.Y. (2011) Rheumatoid Arthritis in Burkina Faso: Clinical and Serological Profiles. Clinical Rheumatology, 30, 1617-1621. https://doi.org/10.1007/s10067-011-1831-1

[5] Fu, X., Li, Z.J., Yang, C.J., Feng, L., Sun, L., Yao, Y. and Huang, Y.T. (2017) The 
Prevalence of Depression in Rheumatoid Arthritis in China: A Systematic Review. Oncotarget, 8, 53623-53630. https://doi.org/10.18632/oncotarget.17323

[6] Masood, A., Salim, B., Nasim, A., Khalid, Z. and Afzal, A. (2017) Are We Missing the Diagnosis of Depression in Patients with Rheumatoid Arthritis at Atertiary Care Facility? Pakistan Journal of Medical Sciences, 33, 300-305. https://doi.org/10.12669/pjms.332.11856

[7] Jamshidi, A.R., Banihashemi, A.T., Paragomi, P., Hasanzadeh, M., Barghamdi, M. and Ghoroghi, S. (2016) Anxiety and Depression in Rheumatoid Arthritis: An Epidemiologic Survey and Investigation of Clinical Correlates in Iranian Population. Rheumatology International, 36, 1119-1125. https://doi.org/10.1007/s00296-016-3493-4

[8] Tekaya, R., Saadi, F., Mahmoud, I., Saidane, O., Abdelmoula, L., Chaabouni, L. and Zouari, R. (2012) Assessment of Depression in Rheumatoid Arthritis: A Cross Sectional Study on 60 Patients. La Presse Médicale, 41, e220-e225.

https://doi.org/10.1016/j.lpm.2011.10.029

[9] Matcham, F., Ali, S., Irving, K., Hotopf, M. and Chalder, T. (2016) Are Depression and Anxiety Associated with Disease Activity in Rheumatoid Arthritis? A Prospective Study. BMC Musculoskeletal Disorders, 17, 155.

https://doi.org/10.1186/s12891-016-1011-1

[10] Ang, D.C., Choi, H., Kroenke, K. and Wolfe, F. (2005) Comorbid Depression Is an Independent Risk Factor for Mortality in Patients with Rheumatoid Arthritis. Journal of Rheumatology, 32, 1013-1019.

[11] Aletaha, D., Neogi, T., Silman, A.J., Funovits, J., Felson, D.T., Bingham, C.O., et al. (2010) Rheumatoid Arthritis Classification Criteria: An American College of Rheumatology/European League against Rheumatism Collaborative Initiative. Arthritis Rheumatology, 62, 2569-2581. https://doi.org/10.1002/art.27584

[12] Hamilton, M. (1960) Rating Scale for Depression. Journal of Neurology, Neurosurgery \& Psychiatry, 23, 56-62. https://doi.org/10.1136/jnnp.23.1.56

[13] Hamilton, M. (1967) Development of a Rating Scale for Primary Depressive Illness. British Journal of Social and Clinical Psychology, 6, 278-296. https://doi.org/10.1111/j.2044-8260.1967.tb00530.x

[14] Guillemin, F., Briancon, S. and Poureil, J. (1991) Mesure de la capacité fonctionnelle dans la polyarthrite rhumatoïde: Adaptation française du Health Assessment Questionnaire (HAQ). Revue du rhumatisme et des maladies ostéo-articulaires, 58, 459-465.

[15] Van Gestel, A.M., Prevoo, M.L., van't Hof, M.A., van Rijswijk, M.H., van de Putte, L.B. and van Riel, P.L. (1996) Development and Validation of the European League against Rheumatism Response Criteria for Rheumatoid Arthritis. Comparison with the Preliminary American College of Rheumatology and the World Health Organization/International League against Rheumatism Criteria. Arthritis Rheumatology, 39, 34-40. https://doi.org/10.1002/art.1780390105

[16] Wang, S.L., Chang, C.H., Hu, L.Y., Tsai, S.J., Yang, A.C. and You, Z.H. (2014) Risk of Developing Depressive Disorders Following Rheumatoid Arthritis: A Nationwide Population-Based Study. PLOS ONE, 9, e107791.

https://doi.org/10.1371/journal.pone.0107791

[17] Jacob, L., Rockel, T. and Kostev, K. (2017) Depression Risk in Patients with Rheumatoid Arthritisin the United Kingdom. Rheumatology and Therapy, 4, 195-200.

[18] Cabrera-Marroquín, R., Contreras-Yáñez, I., Alcocer-Castillejos, N. and Pascual-Ramos, V. (2014) Major Depressive Episodes Are Associated with Poor Con- 
cordance with Therapy in Rheumatoid Arthritis Patients: The Impact on Disease Outcomes. Clinical and Experimental Rheumatology, 32, 904-913.

[19] Dimatteo, M.R., Lepper, H.S. and Croghan, T.W. (2000) Depression Is a Risk Factor for Noncompliance with Medical Treatment Meta-Analysis of the Effects of Anxiety and Depression on Patient Adherence. Arch Intern Med, 160, 2101-2107. https://doi.org/10.1001/archinte.160.14.2101

[20] Lin, M.C., Guo, H.R., Lu, M.C., Livneh, H., Lai, N.S. and Tsai, T.Y. (2015) Increased Risk of Depression in Patients with Rheumatoid Arthritis: A Seven-Year Population-Based Cohort Study. Clinics, 70, 91-96.

https://doi.org/10.6061/clinics/2015(02)04 